\title{
Increase of Ship Fuel Consumption Due to the Added Resistance in Waves
}

\author{
Nastia Degiuli ${ }^{*}$, Ivan Ćatipović2 ${ }^{2}$ Ivana Martic ${ }^{3}$, Andreja Werner ${ }^{4}$, Većeslav Črić ${ }^{5}$ \\ ${ }^{1}$ Department of Naval Architecture, Faculty of Mechanical Engineering and Naval Architecture, \\ University of Zagreb, Ivana Lučića 5, Zagreb, Croatia \\ e-mail: nastia.degiuli@fsb.hr \\ ${ }^{2}$ Department of Naval Architecture, Faculty of Mechanical Engineering and Naval Architecture, \\ University of Zagreb, Ivana Lučića 5, Zagreb, Croatia \\ e-mail: ivan.catipovic@fsb.hr \\ ${ }^{3}$ Department of Naval Architecture, Faculty of Mechanical Engineering and Naval Architecture, \\ University of Zagreb, Ivana Lučića 5, Zagreb, Croatia \\ e-mail: ivana.martic@fsb.hr \\ ${ }^{4}$ Department of Naval Architecture, Faculty of Mechanical Engineering and Naval Architecture, \\ University of Zagreb, Ivana Lučića 5, Zagreb, Croatia \\ e-mail: andreja.werner@fsb.hr \\ ${ }^{5}$ Department of Naval Architecture, Faculty of Mechanical Engineering and Naval Architecture, \\ University of Zagreb, Ivana Lučića 5, Zagreb, Croatia \\ e-mail: veceslav.coric@fsb.hr
}

Cite as: Degiuli, N., Ćatipović, I., Martić, I., Werner, A., Čorić, V., Increase of Ship Fuel Consumption Due to the Added Resistance in Waves, J. sustain. dev. energy water environ. syst., 5(1), pp 1-14, 2017 , DOI: http://dx.doi.org/10.13044/j.sdewes.d5.0129

\begin{abstract}
Added resistance in waves is the second-order steady force dependant on the ship motions. It significantly affects ship operability and causes speed loss. Therefore the required power and fuel consumption of a ship advancing in a seaway increase. In this paper, additional fuel consumption is approximated in relation to the increased resistance, i.e. the difference between the ship resistance in calm water and resistance while operating in waves. Ship advancing in regular head waves with different speeds is examined. Calm water resistance is calculated according to the potential flow theory and ITTC 1957 model-ship correlation line. The added resistance in waves is calculated using three-dimensional boundary element method based on the potential flow theory. Motion induced resistance due to heave and pitch motions as well as reflection induced resistance are taken into account. Therefore, overall assessment of added resistance in regular waves is achieved through evaluation of the ship drift forces and quadratic transfer function. The so-called near-field formulation is used to determine wave loads acting on the ship hull. Evaluation of increased fuel consumption is made on the basis of estimated added resistance for different speeds and wave frequencies. Correlation of fuel consumption with various wave frequencies that the ship may encounter in its voyage is obtained.
\end{abstract}

\section{KEYWORDS}

Added resistance, Potential flow, Regular waves, Fuel consumption, Panel method, Quadratic transfer function.

\footnotetext{
* Corresponding author
} 


\section{INTRODUCTION}

Ship added resistance in waves as a part of a total resistance is caused by encountering the waves. When a ship navigates in waves, due to increasing resistance the forward speed of the ship decreases. The total resistance is composed of resistance in calm water constant at a given speed and added resistance in waves [1]. Therefore to maintain the ship forward speed, engine power and fuel consumption increase. Added resistance in waves has recently become of great importance considering the increasing demands on the speed and voyage duration of the sailing merchant ships. Because of that, it is necessary to determine the added resistance in waves with great accuracy. More accurate ship performance evaluation in actual sea is essential not only from an economic but also an environmental aspect [2]. It is possible to predict the fuel consumption and costs [3,4] along with the Carbon dioxide $\left(\mathrm{CO}_{2}\right)$ emission during the ship voyage at different sea states and thus choose the voyage regime with the highest economic benefit [5]. Even the empirical approach in fuel consumption estimations can give reasonably good predictions [6]. Fuel consumption and thus gas emissions can be predicted based on statistical data collected on modern ships by monitoring systems [7]. However, the fuel consumption and emission of $\mathrm{CO}_{2}$ when it comes to ships, is highly dependent on ocean and weather conditions, sailing routes and regimes [8]. In order to reduce the $\mathrm{CO}_{2}$ emission International Maritime Organization (IMO) adopted the Energy Efficiency Design Index (EEDI) for new ships. Since added resistance in waves causes increased fuel consumption and $\mathrm{CO}_{2}$ emission, the precise determination of added resistance becomes necessary [9].

Added resistance in waves can be approximately determined using empirical equations [10]. Many numerical and theoretical methods have also been developed however with relatively limited application. Currently, many methods used for the added resistance determination are based on the linear potential flow theory, boundary elements and/or Green's function [11]. Some of the methods are based on the ship strip theory. According to some studies, the strip method provides sufficient accuracy as long as the radiation wave effect is dominant but needs to be corrected for the added resistance due to bow wave diffraction in short waves [12]. Ship motions in short waves are small so the largest contribution to added resistance in waves comes from wave diffraction. There are correction methods that take into account the wave diffraction in short waves [13]. Also there are devices developed to reduce the added resistance in waves due to wave reflection [14]. By reducing the added resistance by $18 \%$ in the object condition, the amount of $\mathrm{CO}_{2}$ emission is consequently reduced by $2 \%$ [14]. It is important to relate the added resistance and the wave amplitude function. Careful attention must be paid in measuring or predicting wave amplitudes since the slight error in the wave amplitude may result in significant difference in added resistance [15].

When a ship is oscillating in waves, the damping is caused by the energy spent and transmitted by the generated waves which causes increase of the ship resistance. Added resistance is mainly caused by hydrodynamic damping of heave and pitch motions [16]. It is important to accurately predict the ship motions in waves in order to determine the ship added resistance [17]. A part of the added resistance caused by wave diffraction is significant at high wave frequencies while the viscous damping can be neglected [18].

The ship speed loss also arises due to some additional causes such as: resistance due to the wind acting on the hull and superstructure, resistance due to the diffraction of waves, efficiency reduction of the propulsion system caused by propeller operating in different conditions from those in calm water as well as due to ship manoeuvrability characteristics. In severe sea states an operating propeller can cause additional dynamic loads and thrust loss which can roughly be approximated or estimated by experimental 
results [2]. An increase of the ship resistance in a seaway can reach up to $15-30 \%$ and it is mainly caused by added resistance in waves [18].

Nakayama et al. [19] presented a time domain simulation method for the wave-induced motions of a towed ship and the towline tension in head seas. The added resistance in waves was obtained from model test results.

In this paper, the effect of added resistance in waves on additional ship fuel consumption is presented. Ship added resistance is calculated for various speeds and different incoming wave frequencies and compared with experimental data for the container ship model available in the literature [19]. The analysis is conducted using hydrodynamic software [20] and added resistance in waves is obtained by the direct integration of the second-order pressure components along the wetted surface.

\section{CALM WATER RESISTANCE}

The lowest approximation of the Navier-Stokes equations is the Laplace equation which is valid under assumptions that the fluid flow is steady, inviscid and irrotational. Despite the above mentioned limitations, the Laplace equation has many applications. The numerical solution of the Laplace equation for simulating the flow over near real configurations has remained a basic method in many engineering design activities, the so called panel method or Boundary Element Method (BEM). The main advantage of the BEM is its unique ability to provide a complete solution in terms of boundary values but with substantial savings in modelling efforts.

The total resistance of the ship consists of viscous and wave resistance. Viscous resistance consists of friction resistance and viscous pressure resistance and for practical calculations the viscous resistance is calculated through the frictional resistance and a form factor which depends on the shape of the hull. The frictional resistance is calculated using the model-ship correlation line ITTC 1957, which includes the effect of three-dimensional flow.

The form factor depends on the hull form and is independent of the Reynolds number and is the same for all similar models and ships. The size of the form factor has an influence on the model-to-ship extrapolation process and the estimation of the total ship resistance. Methods of estimating the form factor are experimental, numerical and empirical. Many researchers have proposed empirical formulae for calculating the form factor based on model test results which may be used for practical purposes. The form factor is assumed to be constant over the speed range and between model and ship [21]. Holtrop proposed formula for the form factor of the hull by regression analysis that takes into account both the form effect on pressure and friction.

The ship resistance is assessed by in-house free surface potential flow code based on the nonlinear ship wave theory. The in-house computer code calculates the steady inviscid flow around a ship hull, the wave pattern and the wave resistance. It solves the exact, fully non-linear potential flow problem by an iterative procedure, based on a raised panel method. The main advantage is the very short calculation time required by these methods, compared to Reynolds-Averaged Navier-Stokes (RANS) equations solvers.

The applied method is based on the nonlinear ship wave calculation using the Raised Panel Iterative Dawson (RAPID) approach, developed at MARIN [22]. An iterative procedure is used, consisting of a sequence of linear problems, defined such that convergence to the solution of the complete steady nonlinear problem is obtained. The Laplace problem in each iteration is solved using constant-strength source panels located at a distance above the free surface; and the combined free surface condition is treated using an essentially DAWSON-like method, modelling derivatives of velocities by means of a difference scheme. Details of the procedure can be found in [22, 23]. 


\section{ADDED RESISTANCE IN REGULAR WAVES}

Added resistance in waves is determined by the drift force as the mean value of second-order wave loading through Quadratic Transfer Function (QTF). In accordance with the momentum equation, some of the wave energy is transferred to the ship in waves. Since only the head waves were taken into account in performed calculations, drift force acts in negative direction of longitudinal axis of the ship coordinate system. Numerical approximation of motions induced by the drift loads demands determination of the second-order wave loads at different frequencies of incoming waves. The low-frequency loads can be determined by the QTF of the incoming waves and diffraction/radiation wave fields. The QTF of the second-order wave load is based on drift forces in regular waves. Therefore, it is necessary to determine QTF in order to solve the second-order wave loads problem.

The complete low-frequency wave loads are composed of two parts: one depending on the quadratic products of the first-order wave fields, and the second depending on the second-order incoming and diffraction potentials, which can be determined by the second-order Froude-Krylov force and Haskind integral on the hull surface, as follows [24]:

$$
F\left(\omega_{i}, \omega_{j}\right)=F_{q}\left(\omega_{i}, \omega_{j}\right)+F_{p}\left(\omega_{i}, \omega_{j}\right)
$$

where $F_{q}\left(\omega_{i}, \omega_{j}\right)$ are first-order loads, $F_{p}\left(\omega_{i}, \omega_{j}\right)$ are second-order loads and $\omega_{i}, \omega_{j}$ are incoming wave frequencies.

In presented approach, the formulation for $F_{p}\left(\omega_{i}, \omega_{j}\right)$ is often called indirect method since it provides a way to evaluate the contribution from the second order diffraction potential through the Haskind relation such that the second-order diffraction potential is not explicitly computed as explained in [25].

Haskind integral enables the replacement of the unknown diffraction potential by the radiation potential [26]:

$$
\iint_{S_{0}} \phi_{7} \frac{\partial \phi_{k}}{\partial n} \mathrm{~d} S_{0}=-\iint_{S_{0}} \phi_{k} \frac{\partial \phi_{0}}{\partial n} \mathrm{~d} S_{0}, k=1 \ldots 6
$$

where $\phi_{7}$ is the diffraction potential, $\phi_{k}$ is the radiation potential, $\phi_{0}$ is the incoming wave potential and $S_{0}$ is the wetted surface.

Diffraction, radiation and incoming wave potential satisfy the boundary conditions on the free surface, bottom and the so called Sommerfeld condition on the radiation waves. By satisfying these conditions the integration area is reduced to the wetted surface.

Considering the QTF to be a regular function of incoming wave frequencies $\omega_{i}$ and $\omega_{j}$ and taking into account the relation $\Delta \omega=\omega_{i}-\omega_{j}$, QTF is developed as Taylor series expansion [10]:

$$
F\left(\omega_{i}, \omega_{j}\right)=F_{0}\left(\omega_{i}\right)+F_{1}\left(\omega_{i}\right) \Delta \omega+F_{2}\left(\omega_{i}\right)(\Delta \omega)^{2} / 2+\ldots
$$

The zeroth-order term $F_{0}\left(\omega_{i}\right)$ represents the load obtained by the integration of the pressure along the hull wetted surface, i.e. the drift force. Approximation proposed by Newman which is generally used when calculating the mentioned term can notably underestimate the second-order wave loads and also can provide an incorrect phase shift given that the approximation is a real function and the QTF is a complex function.

The term $F_{1}\left(\omega_{i}\right)$ is composed of four parts: 


$$
F_{1}\left(\omega_{i}\right)=F_{q}^{1}+F_{p 1}^{1}+F_{p 2}^{1}+F_{p 3}^{1}
$$

where $F_{q}^{1}$ is the contribution of the first-order wave load, $F_{p 1}^{1}$ is the contribution of the second-order incoming wave load and diffraction waves, $F_{p 2}^{1}$ is the second-order correction of the boundary condition on the hull and $F_{p 3}^{1}$ is the effect of forcing pressure over the free surface.

Wave frequencies for finite water depth are determined by the dispersion relation:

$$
\omega=\sqrt{k g \tanh (k d)}
$$

where $k$ is the wave number, $g$ is the acceleration of gravity and $d$ is the depth.

The low-frequency wave loading $F(t)$ is evaluated in temporal domain after the calculation of QTF and complex amplitudes and it is represented by an expression as follows [24]:

$$
F(t)=\Re\left\{\sum_{i=1}^{N} \sum_{j=1}^{N} F_{i j}^{\prime} a_{i} a_{j}^{*} \exp \left[-i\left(\omega_{i}-\omega_{j}\right) t\right]\right\}
$$

where $F_{i j}^{\prime}$ is the drift force in waves, $a_{i}$ is the complex amplitude of incoming wave, $a_{j}^{*}$ is the complex conjugate amplitude of incoming wave and $\omega_{i}, \omega_{j}$ are incoming wave frequencies.

At each time step, the low-frequency wave loading is evaluated to perform the time simulation of motions. Due to the double summation in the eq. (6), the calculation is complex and time-consuming so the Newman's approximation of drift forces in regular waves is largely used in practice:

$$
F_{i j}^{\prime}=\operatorname{sign}\left(F^{\prime}\right) \sqrt{F_{i i}^{\prime} \cdot F_{j j}^{\prime}}
$$

where sign $\left(F^{\prime}\right)$ is the signum function i.e. the sign of wave loading which is assumed to remain the same when $\omega_{j}$ varies.

Finally, after introducing the approximation eq. (7) into the wave loading eq. (6), the time-series reconstruction of low-frequency wave loading becomes:

$$
F(t)=\left|\sum_{j=1}^{N} \sqrt{F_{i j}^{\prime}} a_{j} \exp \left(-i \omega_{j} t\right)\right|^{2} \operatorname{sign}\left(F^{\prime}\right)
$$

where $F_{j j}^{\prime}$ is the wave loading at certain wave frequency or drift force.

The added resistance force in waves is defined as:

$$
F(t)=F_{j j}^{\prime} a_{j}^{2}
$$

where $a_{j}$ is the amplitude of head incoming waves.

The added resistance coefficient is given by the following equation:

$$
C_{x w}=\frac{F(t)}{\rho g a_{j}^{2} B^{2} / L}
$$


where $\rho$ is the density of water, $g$ is the gravity acceleration, $B$ is the model breadth and $L$ is the model length.

In this paper previously described numerical procedure is used to calculate constant part of second-order wave load that represents the added resistance in waves.

\section{CASE STUDY}

\section{Model test description}

On the basis of the presented mathematical model and hydrodynamic software [20], ship added resistance in waves for the S-175 container ship model in regular head waves is calculated for various wave lengths. In order to verify and validate the mathematical model, the obtained results are compared with model test results [19]. Tests were conducted on a stationary model and at three different speeds. Wave height was set to $30 \mathrm{~mm}$ and the ratio between wave length and model length varied in the range $\lambda / L=0.3-2.0$.

The sway and yaw motions of the ship model were fixed by guide equipment, so the slewing motion never occurred. The ship model was free to move in surge and heave directions and it was able to rotate around a lateral axis (pitch). The ship model could experience surge, heave, and pitch motions only. Therefore, it was possible to measure heave, pitch and surge motions of the ship model. The surge and heave motions were measured by laser range-finders and the pitch motion by a potentiometer.

The principal dimensions of the full scale S-175 container ship and its model are given in Table 1 and the body plan is shown in Figure 1. The position of the Longitudinal Centre of Gravity (LCG) and the radius of gyration in Table 1 represent actual measurement values obtained from model tests [19].

Table 1. Principal dimensions of the S-175 container ship

\begin{tabular}{ccc}
\hline & Full scale & Model \\
\hline Length $L[\mathrm{~m}]$ & 175.00 & 3.00 \\
Breadth $B[\mathrm{~m}]$ & 25.40 & 0.435 \\
Draft of fore peak $T_{F}[\mathrm{~m}]$ & 7.00 & 0.120 \\
Draft of midship $T[\mathrm{~m}]$ & 9.50 & 0.163 \\
Draft of aft peak $T_{A}[\mathrm{~m}]$ & 12.02 & 0.206 \\
Displacement volume $\nabla\left[\mathrm{m}^{3}\right]$ & $24,154.13$ & 0.122 \\
Block coefficient $C_{B}$ & 0.572 & 0.572 \\
Position of LCG $x_{G}[\mathrm{~m}]$ & & -0.141 \\
Radius of gyration $k_{y y} / L$ & & 0.239 \\
\hline
\end{tabular}

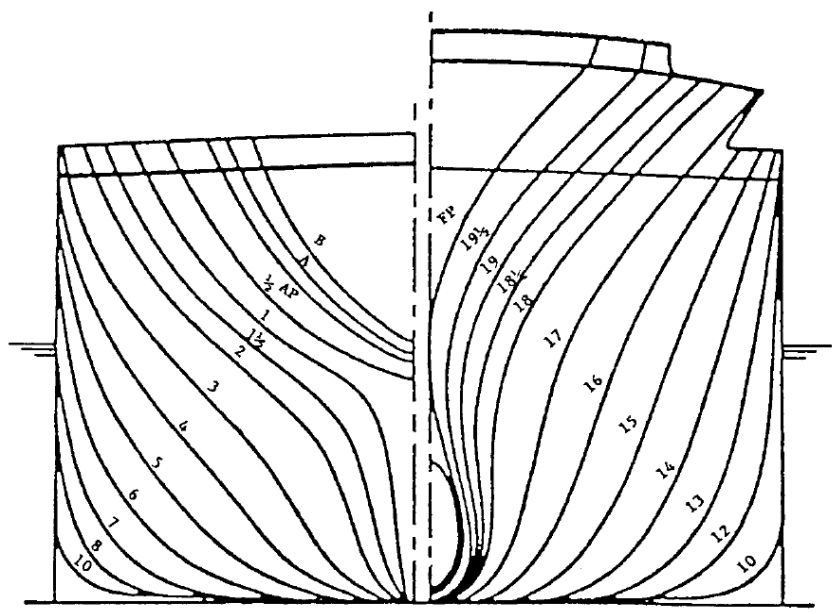

Figure 1. Body plan of the S-175 container ship 


\section{Calm water resistance calculation}

The calm water resistance is assessed by an in-house computer code as described in [27]. The hull panelling consists of 1,280 panels and free surface panelling consists of 1,275 panels for one symmetric half, in total 2,555 panels. Figure 2 shows the hull and free surface panelling for the nonlinear wave resistance calculation as generated by the automatic adaptation. The free surface elevations are ten times magnified.

The form factor $k=0.153$ is calculated according to Holtrop's method for predicting the form factor [21].

The results regarding calm water resistance are given in Table 2.

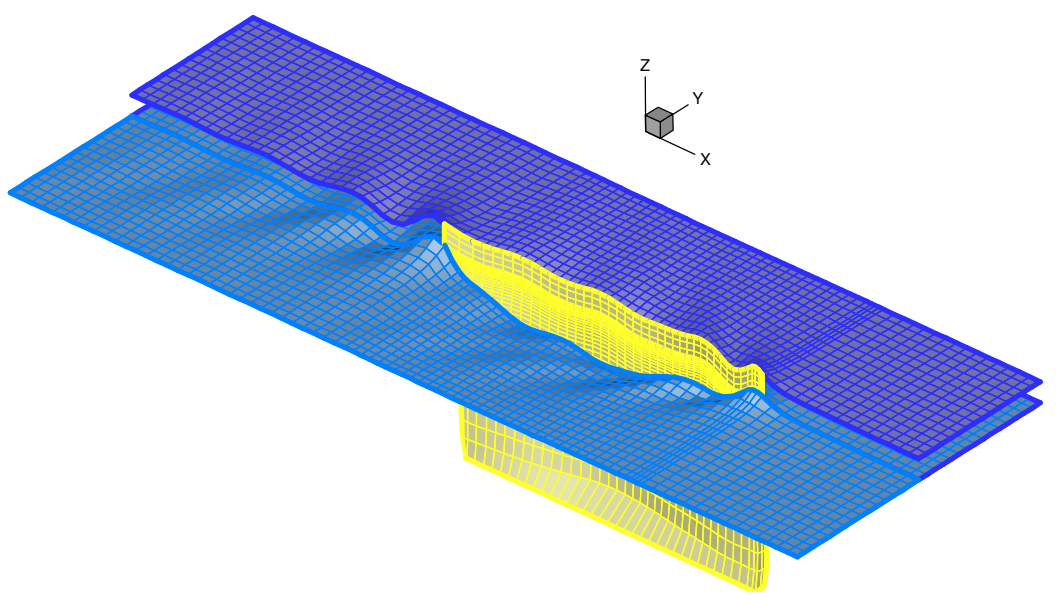

Figure 2. Hull and the free surface panelling for the S-175 container ship model at $F n=0.198$

Table 2. Calm water resistance of the S-175 container ship

\begin{tabular}{ccccccc}
\hline$F n$ & $C_{w} \times 10^{3}$ & $v[\mathrm{~m} / \mathrm{s}]$ & $R n \times 10^{-8}$ & $C_{F} \times 10^{3}$ & $C_{T} \times 10^{3}$ & $R_{T}[\mathrm{kN}]$ \\
\hline 0.087 & 0.0849 & 3.604 & 5.3077 & 1.6584 & 1.9970 & 71.3766 \\
0.148 & 0.2318 & 6.131 & 9.0292 & 1.5502 & 2.0192 & 208.8475 \\
0.198 & 0.4932 & 8.202 & 12.080 & 1.4954 & 2.2173 & 410.4827 \\
\hline
\end{tabular}

Figure 3 shows the three-dimensional steady wave pattern around the S-175 container ship model at $F n=0.198$. The wave heights are ten times magnified and normalized by the length of the ship model.

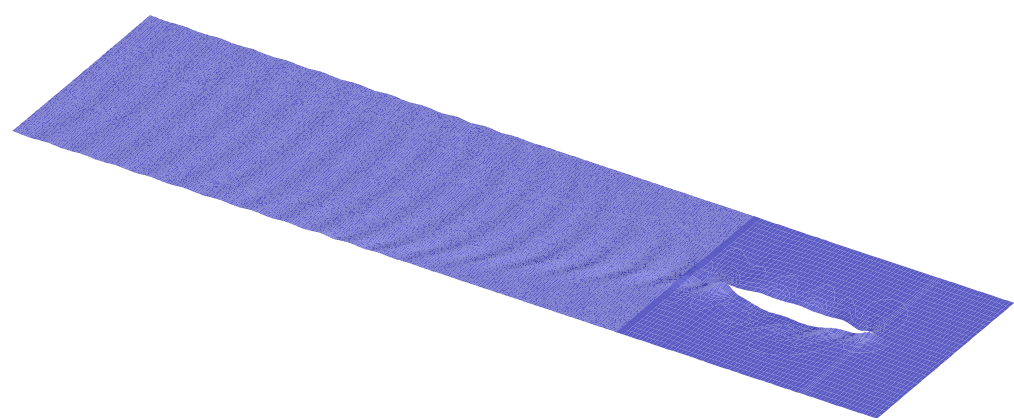

Figure 3. Wave pattern around the S-175 container ship model at $F n=0.198$

\section{Added resistance calculation}

Hydrodynamic software [20] used for calculations is based on the linear potential flow theory and it provides a complete solution of the first-order problem of wave diffraction and radiation and also the QTF of second-order low-frequency wave loads for 
floating body with or without forward speed in deep water and in water of finite depth. The software uses panel method based on the boundary integral equations.

Once the hull form is defined, the software creates a hull mesh under the waterline. Visualization of the mesh for the S-175 container ship model as obtained by the software is shown in Figure 4.

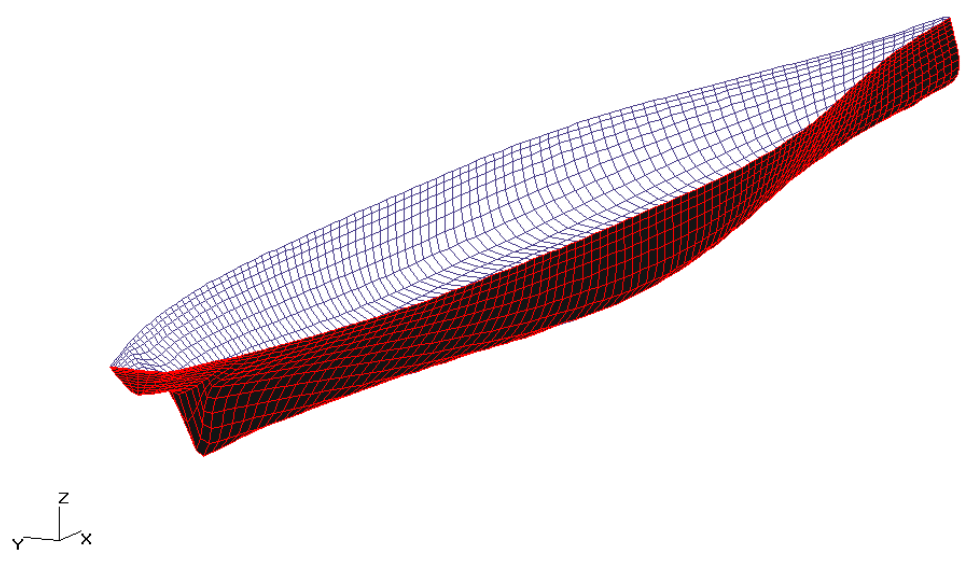

Figure 4. The S-175 container ship model mesh

Based on model test results [19], the regular head waves having the constant wave height of $30 \mathrm{~mm}$ with incoming wave frequencies based on the defined ratios $\lambda / L$ were applied. The ratio between wave length and model length varied in the range $\lambda / L=0.3-2.0$, with step size 0.1 . Incoming wave frequencies, for which the calculations were performed, were determined using the dispersion relation (5) for finite water depth, considering that the towing tank depth equals $3.5 \mathrm{~m}$.

The calculation was performed for four Froude numbers given in Table 3.

Table 3. Froude numbers and corresponding model speeds

\begin{tabular}{cc}
\hline Froude number $F n$ & Model speed $v[\mathrm{~m} / \mathrm{s}]$ \\
\hline 0 & 0 \\
0.087 & 0.472 \\
0.148 & 0.803 \\
0.198 & 1.074 \\
\hline
\end{tabular}

Second-order low-frequency wave loads using hydrodynamic software can be solved using three formulations [20]:

- The near field formulation requires the evaluation of the first-order wave field around the hull and along the waterline, as well as the first-order motions caused by that field. Drift load is determined by direct numerical integration of pressure along the defined hull form wetted surface. Longitudinal components of the oscillating hydrodynamic pressure are integrated along the wetted surface. The pressure integration consists of two parts: pressure integration along the wetted surface defined by mean position of the ship since the first order effects cause mainly the motion responses, and the integration of the pressure cause by changing wetted surface area due to ship motions in waves. The diffraction-radiation problem is solved by Green's function source distribution method. Using the dynamic free surface boundary condition, pressure in hull panels along the waterline is obtained and the relative wave elevation is determined based on the total motions of the ship related to the wave elevation; 
- Another formulation based on the momentum theorem for the horizontal drift forces involves first-order wave field in the far field and is often called far field formulation and is preferable in practice thanks to its better convergence of drift forces and stability. However, the far field formulation cannot provide the accurate vertical drift loads and the low-frequency loads QTF which can be both of great importance in shallow water. The method is considering a control volume around the hull and since the incoming wave potential is familiar it is necessary to calculate the potential that satisfies the linearized free surface condition and ship hull boundary condition. The force acting on the ship hull is determined through momentum flow through the control volume around the hull. The wave field potential consists of the regular wave field potential and the potential determined with the singularities that represent the ship hull;

- The middle field formulation combines the advantages of both near field and far field formulation providing sufficiently accurate numerical results and possibility of calculating all components of drift loads and low-frequency loads QTF as the near field formulation. The method is based on the analysis in a finite volume limited by the hull and a control surface surrounding the hull. Pressure integration over the hull surface is evaluated with a semi-analytical method using the far field potentials like the previous formulation. Gauss theorem is applied to control volume limited by a control surface around the ship hull. Horizontal components of drift loads involve a surface integral on the mentioned control surface and a line integral along the intersection of the control surface and the free surface.

\section{RESULTS}

Comparison of the calculated added resistance coefficients in regular head waves with coefficients obtained from model test results, as a function of the ratio between wave length and model length, is shown in Figures 5-8. In the Figures 5-8 only the results obtained by direct numerical integration of pressure along the defined hull form wetted surface are given, since near and middle field formulations give identical results. The results obtained by far field formulation differ significantly from the results obtained by two previously mentioned formulations. Also evaluation of the second-order wave loads using the far field formulation based on momentum theorem gives the highest deviations from experimental results. Considering that it is a formulation that uses far potentials, it does not provide sufficiently accurate results in finite water depth (which was the assumption of this analysis). It is obvious that by increasing the ship speed or Froude number, the deviations between numerical and experimental results also increase.

Part of the ship resistance is accounted for by the aerodynamic drag of the superstructure and the above water part of the hull. Since only a moderate sea state is considered, added resistance due to wind can be neglected [28]. According to [28] the contribution from the wind is quite small compared with the increase in resistance due to the waves in moderate sea state.

Additional fuel consumption for full scale ship in regular head waves as a function of the ratio between wave length and model length for different Froude numbers is given in Figure 9. The calculation of fuel consumption is made on the basis of added resistance coefficients obtained from model test results. To overcome the added resistance in waves obtained by the hydrodynamic software at given speed, increase in power is required. Based on the required power and specific fuel consumption $(200 \mathrm{~g} / \mathrm{kWh})$ the additional fuel consumption at given speed is obtained as a difference between the real fuel consumption and the one in calm water.

Figure 10 shows the comparison of the increase of fuel consumption in regular head waves over the fuel consumption in calm water as a function of the ratio between wave 
length and model length for different Froude numbers. Since some values reach as much as $85 \%$ of the fuel consumption in calm water, it can be concluded that the added resistance due to waves should be included in total estimation of ship fuel consumption.

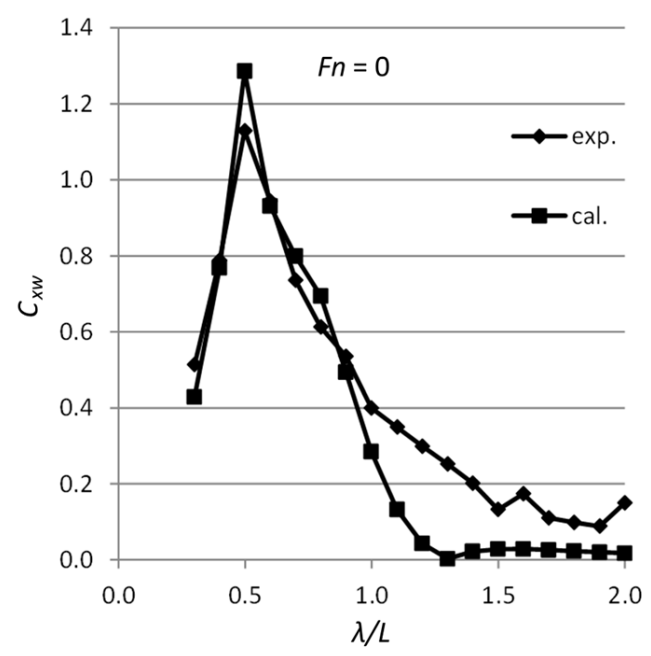

Figure 5. Comparison of added resistance coefficients in regular head waves for $F n=0$

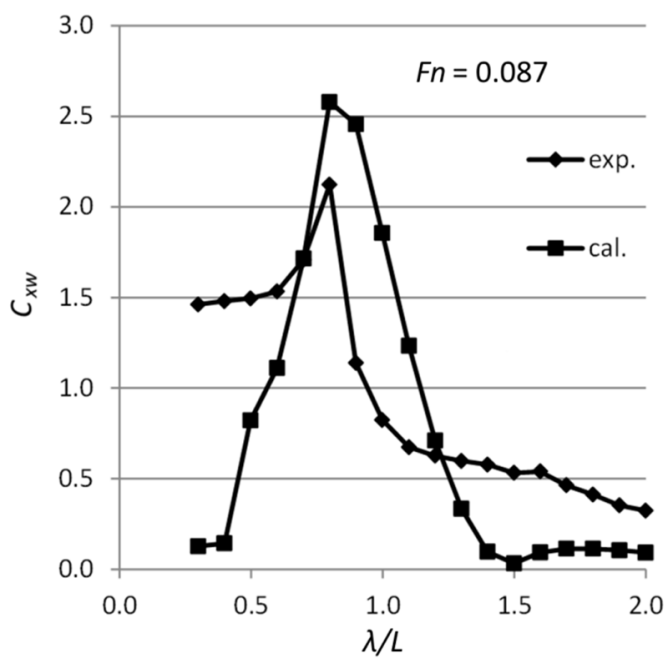

Figure 6. Comparison of added resistance coefficients in regular head waves for $F n=0.087$

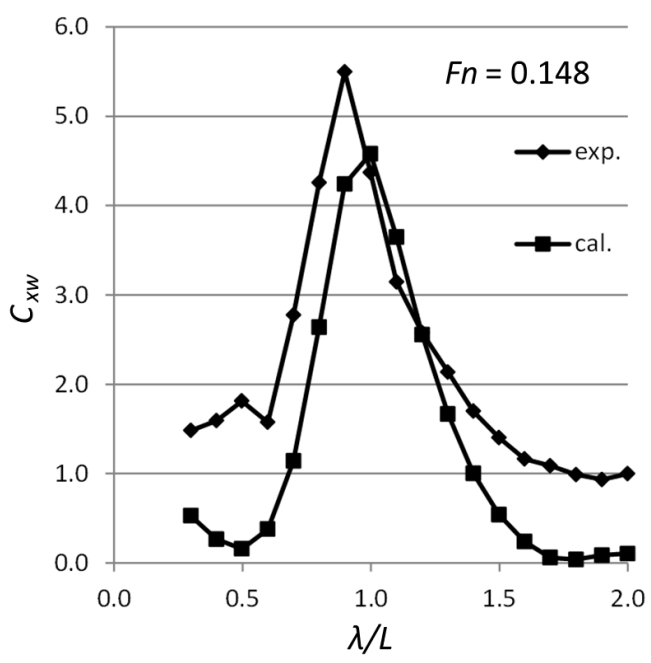

Figure 7. Comparison of added resistance coefficients in regular head waves for $F n=0.148$ 


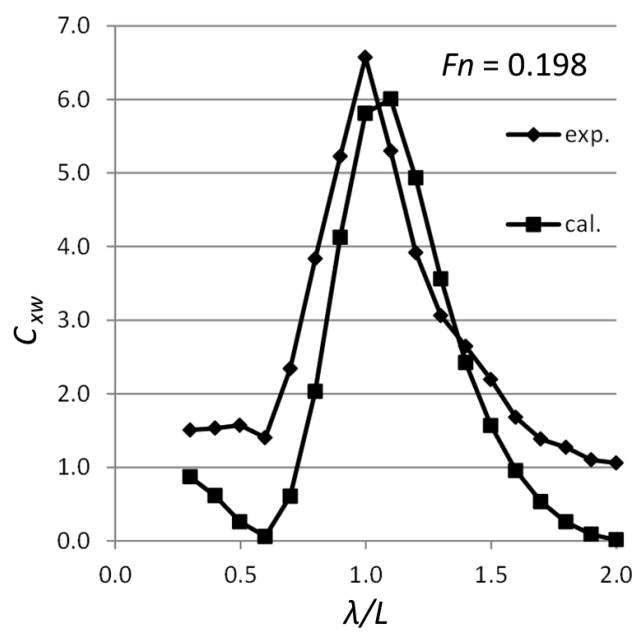

Figure 8. Comparison of added resistance coefficients in regular head waves for $F n=0.198$

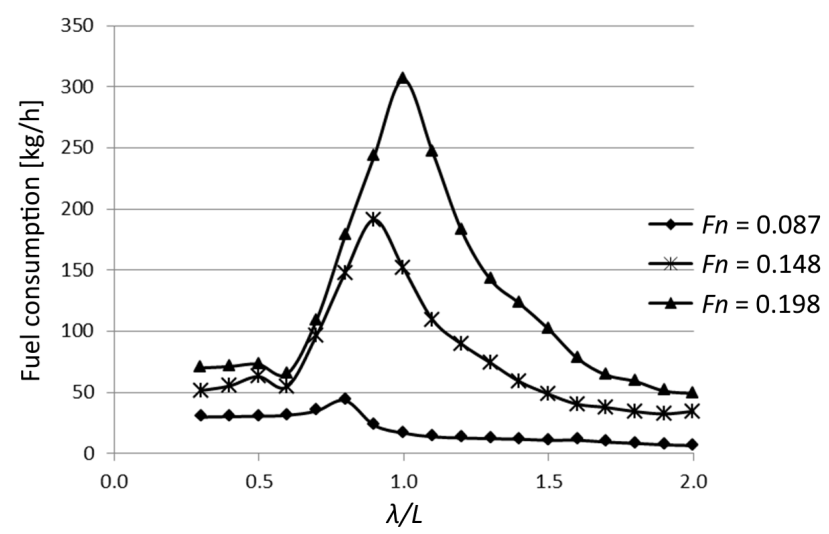

Figure 9. Comparison of additional fuel consumption in regular head waves for different Froude numbers

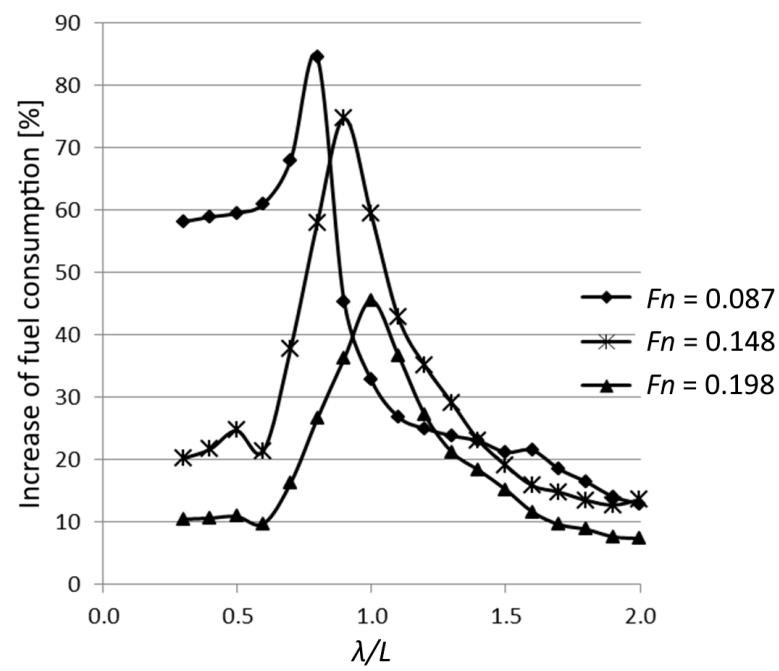

Figure 10. Comparison of the increase of fuel consumption in regular head waves for different Froude numbers

\section{CONCLUSIONS}

The S-175 container ship added resistance in waves is calculated using three-dimensional boundary element method based on the potential flow theory and compared to the available experimental results. The additional fuel consumption due to 
increased resistance is obtained at three different speeds. Correlation between wave frequency and ship fuel consumption is obtained for the presented case study. By overview of the obtained results, it can be concluded that maximum fuel consumption is related to a specific wave frequency or wave length. In other words, shifting from the peak the fuel consumption decreases rapidly. This fact can be very useful when planning the trip of a ship so as to avoid those parts of the waterway where the unfavourable wave frequencies can occur.

The plans for future research is to correlate the sea state or the significant wave height and zero crossing wave period with added resistance in waves i.e. with increased fuel consumption.

\section{ACKNOWLEDGEMENT}

This investigation is done with the support of Towing safety of offshore structures in rough seas funded by University of Zagreb.

\section{NOMENCLATURE}

$a_{i} \quad$ complex amplitude of incoming wave [m]

$a_{j} \quad$ amplitude of head incoming waves [m]

$a_{j}^{*} \quad$ complex conjugate amplitude of incoming wave [m]

$B \quad$ model breadth [m]

$C_{B} \quad$ block coefficient [-]

$C_{x w} \quad$ added resistance coefficient

$d \quad$ depth [m]

$F(t) \quad$ added resistance force $\quad[\mathrm{N}]$

$F\left(\omega_{i}, \omega_{j}\right)$ wave load [N]

$\begin{array}{lll}F_{i j}^{\prime} & \text { drift force in waves } & {[\mathrm{N}]}\end{array}$

$\begin{array}{lll}F_{p} & \text { first-order loads } & {[\mathrm{N}]}\end{array}$

$\begin{array}{lll}F_{q} & \text { second-order loads } & {[\mathrm{N}]}\end{array}$

$F_{0} \quad$ zeroth-order term in wave load [N]

$\begin{array}{lll}F_{1} & \text { first-order term in wave load }\end{array}$

$\begin{array}{lll}F_{p 1}^{1} & \text { contribution of second-order incoming } & \text { wave load and diffraction waves }\end{array}$

$\begin{array}{lll}F_{p 2}^{1} & \left.\begin{array}{l}\text { second-order correction of the boundary } \\ \text { condition on the hull }\end{array}\right]\end{array}$

$F_{p 3}^{1} \quad$ effect of forcing pressure over the free surface $\quad[\mathrm{N}]$

$F_{q}^{1} \quad$ contribution of first-order wave load [N]

$g \quad$ acceleration of gravity $\left[\mathrm{m} / \mathrm{s}^{2}\right]$

$k \quad$ wave number $\quad[1 / \mathrm{m}]$

$k_{y y}$ radius of gyration [m]

$L \quad$ model length [m]

$S_{0} \quad$ wetted surface $\quad\left[\mathrm{m}^{2}\right]$

$T$ draft of midship [m]

$\begin{array}{lll}T_{A} & \text { draft of aft peak }\end{array}$

$T_{F} \quad$ draft of fore peak [m]

$v \quad$ model speed $[\mathrm{m} / \mathrm{s}]$

$x_{G} \quad$ position of LCG [m]

\section{Greek letters}

$\lambda \quad$ wave length

$\rho \quad$ density $\quad\left[\mathrm{kg} / \mathrm{m}^{3}\right]$




$\begin{array}{llc}\phi_{k} & \text { radiation potential } & {\left[\mathrm{m}^{2} / \mathrm{s}\right]} \\ \phi_{7} & \text { diffraction potential } & {\left[\mathrm{m}^{2} / \mathrm{s}\right]} \\ \omega_{i} & \text { incoming wave frequency } & {[\mathrm{rad} / \mathrm{s}]} \\ \omega_{j} & \text { incoming wave frequency } & {[\mathrm{rad} / \mathrm{s}]} \\ \nabla & \text { displacement volume } & {\left[\mathrm{m}^{3}\right]}\end{array}$

\section{REFERENCES}

1. Prins, H., Time-domain Calculations of Drift Forces and Moments, PhD Thesis, Delft University of Technology, The Netherlands, 1995.

2. Prpić-Oršić, J. and Faltinsen, O. M., Estimation of Ship Speed Loss and Associated $\mathrm{CO}_{2}$ Emissions in a Seaway, Ocean Engineering, Vol. 44, No. 1, pp 1-10, 2012, http://dx.doi.org/10.1016/j.oceaneng.2012.01.028

3. Kowalski, A., Cost Optimization of Marine Fuels Consumption as Important Factor of Control Ship's Sulfur and Nitrogen Oxides Emissions, Scientific Journals of The Maritime University of Szczecin, Vol. 108, Issue 36, pp 94-99, 2013.

4. Erto, P., Lepore, A., Palumbo, B. and Vitiello, L. A., Procedure for Predicting and Controlling the Ship Fuel Consumption: Its Implementation and Test, Quality and Reliability Engineering International, Vol. 31, No. 7, SI, pp 1177-1184, 2015, http://dx.doi.org/10.1002/qre.1864

5. Prpić-Oršić, J., Vettor, R., Faltinsen, O. M. and Guedes Soares, C., Influence of Ship Routes on Fuel Consumption and $\mathrm{CO}_{2}$ Emission, Maritime Technology and Engineering -Martech, Lisabon, pp 857-864, 2014.

6. Lu, R., Turan, O. and Boulougouris, E., Voyage Optimisation: Prediction of Ship Specific Fuel Consumption for Energy Efficient Shipping, Proceedings of the $3^{\text {rd }}$ International Conference on Technologies, Operations, Logistics and Modelling for Low Carbon Shipping, London, United Kingdom, 9/09/13 - 10/09/13, pp 1-11, 2013.

7. Bocchetti, D., Lepore, A., Palumbo, B. and Vitiello, L., A Statistical Approach to Ship Fuel Consumption Monitoring, Journal of Ship Research, Vol. 59, No. 3, pp 162-171, 2015, http://dx.doi.org/10.5957/JOSR.59.3.150012

8. Yuan, J., Ng, S. H. and Sou, W. S, Uncertainty Quantification of $\mathrm{CO}_{2}$ Emission Reduction for Maritime Shipping, Energy Policy, Vol. 88, pp 113-130, 2015, http://dx.doi.org/10.1016/j.enpol.2015.10.020

9. Kim, S. O., Ock, Y. B., Heo, J. K., Park, J. C., Shin, H. S. and Lee, S. K., CFD Simulation of Added Resistance of Ships in Head Sea for Estimating Energy Efficiency Design Index, Oceans 2014 Conference, Taipei, pp 1-5, 2014.

10.Prpić-Oršić, J., Nabergoj, R. and Trincas, G., The Methods of Added Resistance Estimation for Ships in a Seaway, Proceedings of the $18^{\text {th }}$ Symposium SORTA 2008, pp 473-483, 2008.

11.Kara, F., Time Domain Prediction of Added Resistance of Ships, Journal of Ship Research, Vol. 55, No. 3, pp 163-184, 2011.

12.Kashiwagi, M., Ikeda, T. and Sasakawa, T., Effects of Forward Speed of a Ship on Added Resistance in Waves, International Journal of Offshore and Polar Engineering, Vol. 20, No. 3, pp 196-203, 2010.

13.Tsujimoto, M., Shibata, K., Kuroda, M. and Takagi, K., A Practical Correction Method for Added Resistance in Waves, Journal of the Japan Society of Naval Architects and Ocean Engineers, Vol. 8, pp 177-184, 2008.

14.Kuroda, M., Tsujimoto, M., Sasaki, N., Omote, M., Nojima, N. and Koga, M., Development of STEP for the Reduction of Added Resistance in Waves, Proceedings of the $22^{\text {nd }}$ (2012) International Offshore and Polar Engineering Conference, Rhodes, Greece, June 17-22, 2012. 
15.Kashiwagi, M., Prediction of Added Resistance by Means of Unsteady Wave-Pattern Analysis, Proceedings of the $25^{\text {th }}$ International Workshop on Water Waves and Floating Bodies, 25 ${ }^{\text {th }}$ IWWWFB, Harbin, China, 2010.

16.Martić, I., Degiuli, N. and Ćatipović, I., Added Resistance in Waves of Intact and Damaged Ship in the Adriatic Sea, Brodogradnja, Vol. 66, No. 2, pp 1-14, 2015.

17.Matulja, D., Sportelli, M., Guedes Soares, C. and Prpić-Oršić, J., Estimation of Added Resistance of a Ship in Regular Waves, Brodogradnja, Vol. 62, No. 3, pp 259-264, 2011.

18.Alexandersson, M., A Study of Methods to Predict Added Resistance in Waves, M.Sc. Thesis, KTH Centre for Naval Architecture, Stockholm, 2009.

19.Nakayama, Y., Yasukawa, H., Hirata, N. and Hata, H., Time Domain Simulation of Wave-induced Motions of a Towed Ship in Head Seas, Proceedings of the $22^{\text {nd }}$ (2012) International Offshore and Polar Engineering Conference, Rhodes, Greece, pp 901-907, 2012.

20.HYDROSTAR for Experts, v6.11 - User Manual, Bureau Veritas, Paris, 2010.

21.Molland, A. F., Turnock, S. R. and Hudson, D. A., Ship Resistance and Propulsion: Practical Estimation of Ship Propulsive Power, Cambridge University Press, New York, 2011, http://dx.doi.org/10.1017/CBO9780511974113

22.Raven, H. C., A Solution Method for the Nonlinear Ship Wave Resistance Problem, Ph.D. Thesis, Technische Universiteit Delft, The Netherlands, 1996.

23.Werner, A., Degiuli, N. and Sutlović, I., CFD as an Engineering Tool for Design and Analysis, Strojarstvo, Vol. 48, No. 3-4, pp 115-121, 2006.

24.Chen, X. B. and Rezende, F., Computations of Low-frequency Wave Loading, Proceedings of the $23^{\text {rd }}$ International Workshop on Water Waves and Floating Bodies, $23^{\text {rd }}$ IWWWFB, Jeju, Korea, 2008.

25.Chen, X. B. and Duan, W. Y., Formulations of Low-frequency QTF by $\mathrm{O}(\Delta \omega)$ Approximation, Proceedings of the $22^{\text {nd }}$ International Workshop on Water Waves and Floating Bodies, Plitvice, Croatia, 15-18 April 2007.

26.Prpić-Oršić, J. and Čorić, V., Pomorstvenost plovnih objekata, Zigo, Rijeka, 2006.

27.Ćatipović, I., Degiuli, N., Werner, A., Čorić, V. and Radanović, J., Numerical Model of Towing Line in Sea Transport, Proceedings of the $33^{\text {rd }}$ International Conference on Ocean Offshore and Arctic Engineering, OMAE 2014, July 2014, San Francisco, USA, 2014, http://dx.doi.org/10.1115/omae2014-24218

28.Lloyd, A. R. J. M., Seakeeping: Ship Behaviour in Rough Weather, Ellis Horwood Ltd Chichester, Sussex, United Kingdom, 1989. 